
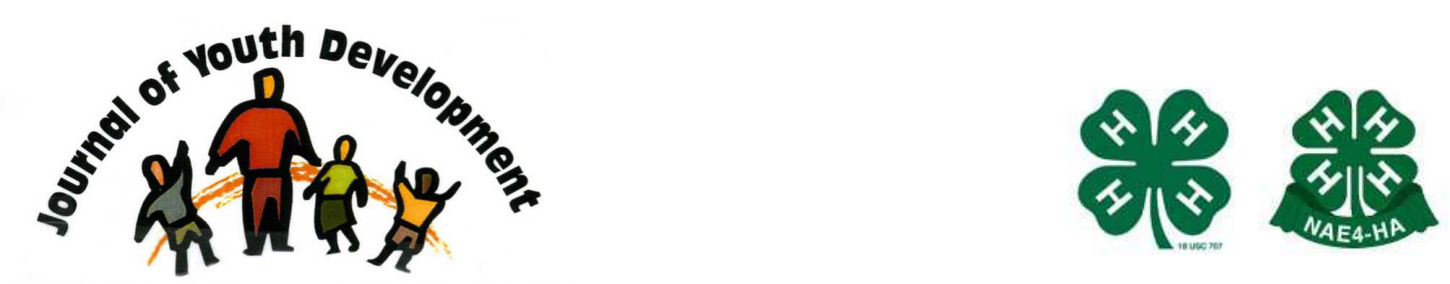

Bridging Research \& Practice

\title{
How Come the Best Job I Ever Had Was When I Worked at a Summer Camp?: Understanding Retention Among Camp Counselors
}

\author{
Jay Whitacre \\ Department of Recreation, Park \& Tourism Studies \\ Indiana University \\ Bloomington, IN \\ jamawhit@indiana.edu \\ James Farmer \\ Department of Recreation, Park \& Tourism Studies \\ Indiana University \\ Bloomington, IN
}




\title{
JOURNAL OF YOUTH DEVELOPMENT \\ bridging research and practice

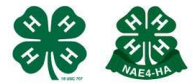

Bridging Research \& Practice

Volume 8, Number 2, Summer 2013

Article 130802FA003

\section{How Come the Best Job I Ever Had Was When I Worked at a Summer Camp?: Understanding Retention Among Camp Counselors}

\author{
Jay Whitacre and James Farmer \\ Indiana University
}

\begin{abstract}
When attempting to discover a manner in which to maintain employment during the summer, many individuals have realized the job of camp counselor. What begins as a seasonal position may transform into a lifelong commitment to both person and place. For years, individuals have come to appreciate and understand the experiences that occur when approaching particular places. Data, for this study, was collected via in-depth interviews from twenty-four camp counselors from three separate, but similar camps. Phenomenological analysis on the qualitative data was performed to explore the staff retention amongst counselors. This study links sense of place as a salient component of employee retention among camp counselors. By developing a strong sense of community amongst staff, camp administrators may be promoting a deeper, more long-term, commitment among the staff and towards the camp.
\end{abstract}

\section{Introduction}

In 2005, the American Camp Association reported that between the 12,000 day and resident camps across the United States, the camp experience for some 12 million campers was facilitated by nearly 1.2 million camp counselors. The same ACA benchmark report also noted that each year a $51 \%$ turnover rate was experienced among camp counselors. Historically, only moderate research has been focused upon the phenomenon of the retention of camp counselors, with a paucity existing in the knowledge base (McCole, 2005).

Variables that influence staff retention at residential summer camps are important considerations for many camp administrators (ACA, 2005). As McKinney, Bartlett, and Mulvaney (2007) suggest, recreation and leisure style agencies, as in the case of summer camps, "are being forced to adapt to, changes in a more mobile and fluctuating workforce, thus 
prompting the need for a deeper comprehension and understanding of staff turnover" (p. 51). Past research in the camping field, in conjunction with various other disciplines, draw parallel conclusions as to what prompts staff retention (Darling-Hammond, 2003; Messmer, 2006; Sheridan, 1992).

Sheridan (1992) found that individuals, "hired in the (accounting) firms emphasizing the interpersonal relationship values stayed longer than those hired in firms emphasizing the work task values" (p. 1050). Sheridan goes on to report that the organizational culture was a stronger predictor for retention than the job market or employee demographics. Messmer (2006) posits the strong connection between managers and employees as a vital component in retaining qualified staff within the finance industry. Most recently, an article in Time suggests that the number one aspect to create a positive work environment is by creating a sense of community (James, 2012). Furthermore, James highlights that, "communities [in the work place], and goals that are mutual rather than individual, make people feel more connected and therefore more happy" (Creating a Community section, para. 5).

Additional discussions in Camping Magazine suggest a multitude of methods that camp administrators can employ in the hope of prompting staff retention: offering positive feedback, treating staff as professionals, and empowering staff to assist in administrative projects (Rothman, 2004). By employing such methods, directors may prompt a sense of ownership of the camp amongst the staff, which in turn leads to a greater commitment to the organization. Further, Byrnes (2004) offers several suggestions for improving staff retention, such as: "Camaraderie, caring and appreciation from the administration, empowerment, ownership in the program, tangible prerequisites, room for growth within responsibilities and positions, safety, and a sense of family and belonging" (p. 6). In such, understanding and attempting to direct variables that may enhance staff retention, camp administrators may promote the continuation of camp tradition, heighten staff training experiences, decrease the amount of energy and resources directed at staff recruitment, as well as, build on the camp community/culture from years past.

One theme that does emerge from the literature on staff retention is based on the notion of community fit and sense of belonging; in other words, Sense of Place. The bond, and sense of place, which we create with spaces can be a powerful tool in outdoor recreation pursuits (Gustafson, 2001). Tuan (1974) first introduced the human bond with places as Topophilia, which he defined as "the affective bond between people and a place or setting" (p.4). Topophilia gained popularity within the sub-discipline of human geography and has since permeated several other areas: social relationships, (Sack, 1997), public land management, (Eisenhauer, Krannich, \& Blahna, 2000), medical issues (Gesler, 1992), urban planning (Hiss 1991) and the summer camp experience (Brown, 2008; Henderson, Bialeschki, \& James, 2007; Knowles, 1992).

Place has been defined in several iterations throughout the past 40 years, heavily dependent on the disciplinary context. Relph (1976), a geographer, suggests that, "place is not simple undifferentiated phenomenon of experience that is constant in all situations, but instead has a range of subtleties and significances as great as the range of human experiences and intentions" (p.26). Tuan (1977) further defined this relationship as, "what begins as undifferentiated space becomes place as we get to know it better and endow it with value" (p.6). Within the context of ecosystem management, Williams and Stewart (1998) suggest that, "to define sense of place is to think of it as the collection of meanings, beliefs, symbols, values, and feelings that individuals or groups associate with a particular locality" (p.19). 
To understand the connection between the camp counseling experience and Sense of Place one must consider the basic notion of what place is and how camp is greater than a space or setting. Gussow (1983) notes that developing space into place "converts any physical location any environment if you will - into a place," not simply a space or setting, but a specific location, time, and experience with deeper meaning (p. 45) Further, places have the ability to define who we were, who we are, and who we hope to be (Greider, \& Garkovich, 1994). The experiences that occur when approaching places can be identified in a multifaceted level by examining the properties of place: location, landscape, and personal involvement, which define the essence of a place (Relph, 1976). When approaching the outdoors and an individual's connectedness to it, Knowles (1992) suggests that the outdoors, such as many camps are situated in, promote the "development of a personal sacred place" (p. 11).

Consequently, the following report details our attempt to understand the factors contributing to staff retention amongst former camp counselors from three varying residential summer camps in southern Indiana, United States. Based on the emergent themes from the qualitative data that was garnered from interviews, we posit that understanding the camp counselor experience through the lens of sense of place provides a framework for potentially understanding a critical component of staff retention and ultimately the camp experience for counselors.

\section{Methods}

This study utilized in-depth telephone interviews and phenomenological analysis on qualitative data to explore the phenomenon of staff retention amongst seasonal camp counselors. Participants were purposely selected to focus on individuals who had been seasonal camp counselors for multiple summers at one of three summer camps in southern, Indiana (Riddick, \& Russell, 2008).

Three summer camps in southern Indiana were chosen because they were residential in nature, located in a remote-natural setting, hired a similar demographic of camp counselors that generally consisted of college-university aged young adults, and all three had existed since the early 1960's at the latest. The three camps were quite similar in physical setting and recreational programming, yet unique in spiritual programming.

All three camps are positioned amongst the wooded hills of southern Indiana, on property greater than 200 acres in size. The camp settings also contain various bodies of water ranging from 2 to 5 acres in pond and lake sizes, as well as a small river that cuts the property of one of the camps. All three camps have cabins for campers' housing, with one utilizing platform tents as well during larger sessions. The three camps share a similar set-up in dining services, with a centralized dining hall serving the entire camp population. The recreational programs at the camps are very similar, concentrating in mainstream camp programs such as horseback riding, canoeing, climbing, high and low ropes, archery, riflery (2 camps), swimming, mountain biking (2 camps), arts and crafts, nature lore, spelunking (2 camps), and evening programs that include games and campfire programs. Though similar in setting, composition, and programming, the three camps are quite diverse regarding core values of spiritual programming. One camp is affiliated with the YMCA movement, promoting Protestant Christian values and beliefs throughout the camping program. A second camp instructs on Catholic and faith based values. The third camp has no religious affiliation or practice. 
In total, 24 individuals participated in the telephone interviews. The phenomenological data analysis included three primary steps:

a) the investigation of the phenomena through informal interviews,

b) identification of general themes / essences of the phenomena, and

c) delineation of essential relationships among the themes (Creswell, 2007).

Step 1 consisted of collecting the data and coding initial concepts, terms, and phrases of the participants' interviews into distinct categories. Initial categories were created consistent with Moustakas' framework for phenomenological coding (1994). Step 2 consisted of organizing the clusters of data from the subsequent categories and analyzing each for emergent themes that existed between the different participant interviews. The emergent themes and phrases contained within the data were then evaluated in conjunction with the original transcription to validate the observed phenomena. Step 3 consisted of two researchers evaluating the phrases, categories, and themes, examining each for internal consistency. This included the review and crosschecking of data between the two researchers, establishing consensus on the coded data and emergent themes. Similar to interpretive biographers, phenomenology views verification and standards as largely related to the researchers' interpretation (Moustakas, 1994). General thematic coding and classification was used on data that was readily quantifiable such as demographics.

\section{Results}

Analysis on interview data from 24 participants who worked for at least two summers at one of the three camps was utilized in this study. Participants' absence from camp was anywhere from one year to 25 years. The discourse was initiated with the following statement: 'What do you remember about working at the summer camp?' The interviews ranged from 15 to 90 minutes in length. The participants' ages ranged from 21 to 48 years of age. The researcher attempted to collect interviews from an equal number of males and females, concluding the study with 12 of each gender. All participants had worked at their respected camps for multiple summers, while most had worked in excess of three consecutive summers. The ethnic characteristic of the group is comprised of two persons who were self-identified as Bi-racial (one participant was African American and Caucasian, one participant was Japanese and Caucasian) and 22 Caucasian participants.

Four distinct themes emerged as potential variables that influenced the former camp counselors to return as seasonal staff, for multiple summers:

a) sense of affiliation with fellow counselors,

b) personal commitment flowing from the individual's experience,

c) sense of ownership and empowerment, and

d) sense of affiliation with the administration.

Each area can be connected to sense of place in the following breakdown.

\section{Sense of Affiliation}

Throughout the study, participants shared examples of the relationships and sense of affiliation /belonging to a community of staff members. All of the participants discussed, in great detail, the sense of affiliation with fellow camp counselors that in turn lead to an overall sense of community. Relph (1976) suggests that, "while every individual may assign self-consciously or 
unselfconsciously an identity to particular places, these identities are nevertheless combined intersubjectively to form a common identity" (p.45).

Participants' general responses such as, it was the people. Like the people who I grew to love and who grew to love me, who made me feel very comfortable as who I was and my place, were found throughout the majority of interviews. One such participant commented that he wanted to return because, It was fun and my friends were going as staff. Others mentioned that the, People were so welcoming, that her time at the camp was a great bonding experience with the staff, and that to work with a group of individuals who were very committed to the children and the family type environment where I felt like those people were my family and I enjoyed working with them was a rewarding experience. Still others emphasized that the, friendships made there were probably a main reason for returning.

Specifically several individuals addressed the notion of the camp community and what it prompted, one counselor stated:

It's a community. That's what was incredibly rewarding; it's an instant community. It was honest, it was pure. It was pure experience of community. And then the canvas that this experience was painted upon included enriching experiences for young people, where you became a role model and a hero, in a very fun and entertaining way, and camaraderie of staff as a transcendent into the interaction with young people, that was an incredibly enriching. I often referred to as how at the end of a summer season I had to go back to the real world, but I firmly believe those people who have had an experience such as I have is that that was the real world. And the world in which we live now is fabricated, is surface, is role-playing, but the purest experience of human relationship was experienced while working at summer camp. "Man. We really rocked as a community."

\section{Personal Commitment Flowing from Individuals' Experiences}

"For most individuals, camp was an enjoyable place to go where they could make friends and have fun participating in outdoor activities. For some campers, camp made a profound difference in their lives by giving them an opportunity to learn and grow in their formative years" (Henderson, et.al, 2007, p.756). Twenty-one of the 24 interviewed staff communicated personal intense counseling experiences that contributed to their retention. Six distinct subcategories emerged in the process of coding the interview transcriptions: (a) opportunities for self-exploration, (b) directional life forces, (c) intangible skills, (d) personal challenge, (e) growth through higher level positions, and ( $f$ ) development of work ethic.

One participant's description of the importance of the camp counselor role when describing his thirty-year tenure as staff:

You develop the capacity to develop goals, and to meet those goals. And I think by working at a camp, you also work with parents, so I think there's the opportunity to develop a lot of your personality skills and how to talk with people, and how to work with them, and gain their trust. And not in a superficial way, but it helps them understand that you're going to take care of their kids. So you develop a lot of skills both in-communication skills, your outdoor environment skills, your camping skills, your management/leadership skills, and it gave me a confidence of who I am today. And it provided me a kind of a "well, I can do that," that type of opportunity. I mean, there are few things where they phase me, with regards to adversity, and it's just kind 
of like, "Okay, how can we get through this?" And part of that is just because some of the people that were my mentors at the camp when I was younger modeled a certain way of being, and for me in that a way to be kind, and certain character traits I would call them, about having integrity and discipline, having felt a sense of service. And a sense of community, and things like that. And so, I think it's part of my personality now.

The camp environment puts individuals in a life situation in which they are given a certain amount of responsibility of both themselves and other members of the camp community. This social experience can lead the counselors to associate the transformation of adult-like responsibilities to the actual camp environment. Goffman (1973) suggests, "a social establishment is any place surrounded by fixed barriers to perception in which a particular kind of activity regularly takes place" (p.238). Individuals have the tendency to associate a place with an emotional or affective bond that accompanies the transformative years (Williams, et al., 1992).

\section{Sense of Ownership and Empowerment}

Fifteen of the 24 respondents discussed a sense of ownership and empowerment in their respective camps both in the years they were on staff and presently. One staff member described leaving one's mark at the camp through painting your name on a building, like up in the rafters. And you can kind of leave your mark there. And I thought that was kind of a cool way that everyone could kind of put their stamp on that place. The sense of providing utility to the camp reoccurred in yet another staff members recollection, I just always felt like it didn't matter what I did at camp, behind the scenes or not, I just wanted to be a part of that energy of helping kids. Finally, a significant sense of ownership can be assumed through the statement of a following counselor:

It was definitely like this is my place and anytime I talk about camp to people that worked there, it's my camp. It's where I worked. I still get jealous when people talk about being there and I can't be there anymore. I get very frustrated that that's no longer where I am and that I can't be there. It makes me very sad. To me, that's my place. Its stories and traditions to pass on, that is our responsibility to pass as much. And so it definitely gives you a boost and it makes you comfortable that yes this is my place.

This further supports the notion that the camp environment creates a sense of place within the camp counselors' over their tenure as staff. Gustafson (2001) suggests that "places often become meaningful because of the respondents' relations with people living there - friends, acquaintances, relatives - and the sense of community that such social relations create" (p.9).

\section{Sense of Affiliation with Administration}

Another characteristic that surfaced during the course of this study was the relationship that the camp counselors felt with the administration. Fourteen of the 24 respondents discussed the importance of their relationship to the camp administrators. The respondents, on numerous occasions, denoted the importance of camp administration and the counselor / administration relationship with such comments as, I would have to say the directors themselves, the way that they handled the staff in a lot of ways brought me back.

A staff member that worked at the camp for over 30 summers discussed the importance of his relationship to the camp owner/director. 
My favorite part, was that the relationship that I had with the camp director, who had the compassion to be able to kind of make me feel like an extended part of his family. It was my relationship with the camp director. I think that relationship is what drew me back. That relationship with the camp director, the camp director's wife, the camp director's daughter, no puns intended, and others. I mean, I think it all-and the children. The relationships are what drew me back.

The powerful association that individuals form with places has the ability to catapult the staff into the genre of created ownership in the entire camp atmosphere. Relph (1976) states, "[places] are important sources of individual and communal identity, and are often profound centers of human existence to which people have deep emotional and psychological ties" (p.141).

\section{Discussion}

With staff turnover in the camping industry reaching percentages greater than $51 \%$ of the workforce, the illumination and comprehension of the variables promoting or hindering staff retention is vital. DeGraff and Glover (2003) cite an American Camp Association survey in which $40 \%$ of camp administrators noted staff recruitment and retention as their greatest concern. DeGraff and Glover further note that with a better understanding of the staff experience, "camp directors may be able to create a better working environment that should enhance job satisfaction for the staff" (p. 2). In turn, this may perpetuate a better camping experience for the campers attending the camp programs.

The results presented in this study have the ability to enhance the characteristics of the camp counselor experience; which in turn, can allow camp administration to acknowledge what way to best retain their staff. As with most research of this style, it is not the intent to generalize the results of this study to the entire industry, but instead capture the representative importance of the work experience that emerged as a potential contribution to retention and understanding the essence of the experience. The nature of this study utilized three different camps based on similar models, reaching saturation at the point interviews were discontinued. Finally, the retrospective nature of the camp counselor interviews may lend to prospective limitations with regards to the depth of recollection that the participants' recalled during the interview process.

The emergent themes from this study suggest important factors that likely contributed to the decision of the study's participants to return to the camp for multiple summers of employment, factors parallel to those discussed prior. Among the four emergent themes, staff camaraderie and community are discussed in the greatest strength, depth, and richness throughout all of the participant interviews. The experiences detailed throughout the interviews depict a sense of: family, equality, community, and togetherness as reflected upon regarding the experience of being a camp counselor.

This bond that is created within the camp work environment can be considered a reciprocal relationship that is created between people and nature (Brandenburg, \& Carroll, 1995). Given the intimate nature that is created between camp counselor members leads to moments that can be tied to a particular place. As Tuan (1977) advocates, "Intimacy between persons does not require knowing the details of each other's life; it glows in moments of true awareness and exchange" (p.141). 
It is the connection with a particular place that can allow individuals to create meaning to their social and cultural experiences, thus lending to a growth within the characteristics of the person (Eisenhauer, et al., 2000). The sense of place has been a strong concept within the academic fields of human geography; along with, ecosystem management in the past and can now be linked to camp counselor retention. It is not merely the actual environment that leads to this connection, but the experiences and meanings that are attached to those places (Brown, 2008). On numerous occasions during the interview process, the participants' spoke of the togetherness that surfaced from working intimately with other staff members, which can be linked to the sense of place that is created during the course of their employment. Relations and the sense of familial bonding amongst staff, the director, and the place highlight the community formation on a deeper level. As one staff member noted:

\begin{abstract}
I think that camp provided me a pretty safe environment, and by safe I don't mean physically safe, I mean kind of emotionally safe environment where I felt both that I was valued and I could contribute as well as be industrious. And I could actually feel like I belonged to people. And belonged to what I'd call a larger family. So, and I also think the other thing, my favorite part, was that the relationships that I had with the camp director, who had the compassion to be able to kind of feel like an extended part of his family. I think that what was important again was the relationship I had with staff, the relationship I had with the physical space, as well as the relationship I had with the director and his family, were the three things that brought me back.
\end{abstract}

It is the ability to become rooted in a place that allows individuals to develop a sense of deep care and concern for that place (Relph, 1976). The sense of feeling like an integral part of the overall community can become a powerful tool in maintaining staff retention - not only in seasonal camp counselors - but all organizations that struggle retaining employees. Much literature has focused on the emotional and psychological bonds that form with a particular physical place (Knowles, 1992; Relph, 1976; Stedman, 2003; Tuan, 1974; Tuan, 1977; Williams, Patterson, \& Roggenbuck, 1992), yet little link has been explored in the actual importance of those places in staff retention.

Through the development and fostering of a strong camp community and staff dynamic, camp administrators may in fact be promoting a deeper and more long-term commitment amongst the staff towards the camp. Though the sense of community and camaraderie described by the participants included their interactions with other staff members, the impact and affect of the camping administrators on the community often times enabled the bonds to form (Bialeschki, et al., 1998). Although the camp environment is an obvious setting to perform the outdoor activities, certain specific places have the ability to convey a sense of individual identity and group affiliation (Williams, \& Patterson, 2008).

This is further deepened when staff members return for numerous years by subsequently creating a group of individuals that are able to identify the roles that they can achieve. For it is the right blend of persons and personalities that create this place that people come to understand. For as Tuan (1977) states, "in the absence of the right people, things, and places are quickly drained of meaning so that their lastingness is an irritation rather than a comfort" (p.140). By maintaining the right dynamic of nature, meaning, and social relations we can witness a positive transformation from individual, to community member, to supporter and advocate of that particular place. 


\section{Conclusion}

The sense of place that can develop within the summer camp community has the potential to be a salient element in staff retention. It is an organizational foundation that can be utilized to maintain a work environment that provides employees with a powerful sense of ownership that goes well beyond the tenure of employment. Sack (1997) maintains, "Place then becomes an agent in the formation of the self. But its role continues as the self proceeds in the world" (p.132). The creation of this insight allows employers the understanding that the creation of a sense of place within the organizational setting can allow for a greater level of staff retention.

What seemingly begins as a seasonal position may indeed turn into a lifelong commitment to both person and place. Though small in scope, this study posits the importance of sense of place as an integral component of the camp experience among staff members. Future research on the impact of sense of place development and residential camp counselors should include studies using various methods that provide greater breadth in participants and camp types, in order to develop a deeper comprehension for its potential wide-spread implications for the industry. Finally, this study supports a call for greater exploration of sense of place in the realm of staff retention of not only camp counselors, but also other- similar seasonal staff positions within the leisure industry.

\section{References}

ACA-Camp Trends. (2005). ACA trend fact sheet. Retrieved from http://www.acacamps. org/media_center/camp_trends/fact.php.

Bialeschki, D., Henderson, K., \& Dahowski, H. (1998). Camp gives staff a world of good. Camping Magazine, 71(5), 27-31.

Brandenburg, A.M., \& Carroll, M.S. (1995). Your place or mine?: The effect of place creation on environmental values and landscape meanings. Society and Natural Resources, 8, 381-398.

Brown, M. (2008). Outdoor education: Opportunities provided by place based approach. New Zealand Journal of Outdoor Education, 2(3), 7-25.

Byrnes. (2004). From recruitment to retention: One camp director's secrets to success. Camping Magazine, 776). Retrieved from http://www.acacamps.org/campmag/0411recruit.

Creswell, J.W. (2007). Qualitative inquiry and research design: choosing among five traditions. (Ed. 2). Thousand Oaks, CA: Sage.

Darling-Hammond, L. (2003). Keeping good teachers: Why it matters what leaders can do. Educational Leadership, 60(8), 6-13.

DeGraff, D., \& Glover, J. (2003). Long-Term Impacts of Working at an Organized Camp for Seasonal Staff. Journal of Park and Recreation Administration. 21(1), 1-20.

Eisenhauer, B.W., Krannich, R.S., \& Blahna, D.J. (2000). Attachments to special places on public lands: An analysis of activities, reason for attachments, and community connections. Society \& Natural Resources, 13, 421-441. 
Gesler, W.M. (1992). Therapeutic landscapes: Medical issues in light of the new cultural geography. Social Science Medicine, 34(7), 735-746.

Goffman, E. (1973). The Presentation of self in everyday life. Woodstock, NY: The Overlook Press.

Greider, T., \& Garkovich, L. (1994). Landscapes: The social construction of nature and the environment. Rural Sociology, $59(1), 1-24$.

Gussow, A. (1983). Earth magic. In Matre, S.V. \& Weiler, D., The Earth Speaks. (p.45). Greenville, WV: The Institute for Earth Education.

Gustafson, P. (2001). Meanings of place: Everyday experience and theoretical conceptualizations. Journal of Environmental Psychology, 21, 5-16.

Henderson, K., \& Bialeschki, D. (1991). Research on camp staff experience. Camping Magazine, 64(2), 33-34.

Henderson, K.A., Bialeschki, M.D., \& James P.A. (2007). Overview of camp research. Child and Adolescent Psychiatric Clinics of North America, 16, 755-767.

Hiss, T. (1991). The experience of place: A new way of looking at, and dealing with our radically changing cities and countryside. New York: Vintage Books.

James, G. (2012). Secrets of the World's Happiest Workplace. Time Business. Retrieved from http://business.time.com/2012/08/28/secrets-from-the-worlds-happiest-workplace/?hpt=hp t3.

Knowles, G.J. (1992). Geopiety, the concept of sacred place: Reflections on an outdoor education experience. The Journal of Experiential Education, 15(1), 6-12.

McCole, D. (2005). SEER 2004 Abstract: The influence of sense of community on the retention of seasonal employees. Journal of Experiential Education, 273), 328-329.

McKinney, W.R., Bartlett, K.R., \& Mulvaney, M.A. (2007). Measuring the costs of employee turnover in Illinois public park and recreation agencies: an exploratory study. Journal of Park and Recreation Administration, 25(1), 50-74.

Messmer, M. (2006). Four keys to improved staff retention. Strategic Finance, October, 13-14.

Moustakas, C. (1994) Phenomenological research methods. Thousand Oaks, CA: Sage.

Relph, E. (1976). Place and placelessness. London: Pion Limited.

Riddick, C.C., \& Russell, R.V. (2008). Research in Recreation, Parks, Sport, and Tourism. (Ed. 2). Champaign, IL: Sagamore Publishing.

Rothman, D. (2004). Effective staff recruitment and retention: Or, how to compete when McDonald's is paying $\$ 8$ an hour! Camping Magazine, 772). Retrieved from http://www.acacamps.org/members/knowledge/human/cm/043recruit. 
Sack, R.D. (1997). Homo Geographicus: A framework for action, awareness and moral concern. Baltimore, MD: The John Hopkins University Press.

Sheridan, J. (1992). Organizational culture and employee retention. The Academy of Management Journal, 35(5), 1036-1056.

Stedman, R.C. (2003). Is it really just a social construction?: The contribution of the physical environment to sense of place. Society and Natural Resources, 16(8), 671-685.

Tuan, Y. (1974). Topophilia: A study of environmental perception, attitudes, and values. New Jersey: Prentice-Hall.

Tuan, Y. (1977). Space and place: The perspective of experience. Minneapolis, MN: University of Minnesota Press.

Williams, D.R., \& Patterson, M.E. (2008). Place, leisure, and well-being. In J. Eyles \& A. Williams, Sense of Place, Health and Quality of Life (105-119). Burlington, VT: Ashgate.

Williams, D.R., Patterson, M.E., \& Roggenbuck, J.W. (1992). Beyond the commodity metaphor: Examining emotional and symbolic attachement to place. Leisure Sciences, 14, 29-46.

Williams, D.R., \& Stewart, S.I. (1998). Sense of place: An elusive concept that is finding a home in ecosystem management. Journal of Forestry, 18-23.

(C) Copyright of Journal of Youth Development Bridging Research and Practice. Content may not be copied or emailed to multiple sites or posted to a listserv without copyright holder's express written permission. Contact Editor at: patricia.dawson@oregonstate.edu for details. However, users may print, download or email articles for individual use.

ISSN 2325-4009 (Print); ISSN 2325-4017 (Online) 